Tropical Journal of Pharmaceutical Research January 2021; 20 (1): 11-16

ISSN: $1596-5996$ (print); 1596-9827 (electronic)

(C) Pharmacotherapy Group, Faculty of Pharmacy, University of Benin, Benin City, 300001 Nigeria.

\title{
Ginkgolide K potentiates the protective effect of ketamine against intestinal ischemia/reperfusion injury by modulating NF-KB/ERK/JNK signaling pathway
}

\author{
Weina Zhu ${ }^{1}$, Zhili Zhao ${ }^{2}$, Xiongtao $\mathrm{Liu}^{3}$, Xiumei $\mathrm{Ni}^{3}$, Xiaoming Lei ${ }^{3}$, Xiaoying $\mathrm{Li}^{3}$, \\ Rui Deng ${ }^{3}$, Liyan Zhao ${ }^{3 *}$ \\ ${ }^{1}$ Department of anesthesiology, PLA Air Force 986 Hospital, Xi 'an, Shaanxi 710054, ${ }^{2}$ Department of orthopedics, PLA Air \\ Force 986 Hospital, Xi 'an, Shaanxi 710054, ${ }^{3}$ Department of anesthesiology, The Second Affiliated Hospital of Xi'an Jiaotong \\ University (Xibei Hospital), Xi 'an, Shaanxi 710004, China
}

*For correspondence: Email: 1104924271@qq.com; Tel/Fax: 0086-029-87679237

\begin{abstract}
Purpose: To investigate the effect of ginkgolide $K$ and ketamine treatments, alone and in combination, on intestinal ischemia/reperfusion injury (I/R)-induced injury in rats, as well as the mechanism involved. Methods: Rats were treated with ginkgolide K (GK, $15 \mathrm{mg} / \mathrm{kg}$ i.v) and ketamine (KTM, $100 \mathrm{mg} / \mathrm{kg}$ i.p.), either alone or in combination 30 min before the induction of intestinal I/R. The effects of GK and KTM were determined by assessing the levels of cytokines in serum, and parameters of oxidative stress and ROS production in the intestinal tissues of I/R rats. Moreover, intestinal mRNA expressions of JNK, $E R K, p 38$ and NF-kB were determined by quantitative reverse transcription polymerase chain reaction (qRT-PCR).

Results: GK and KTM treatments, alone and in combination, reduced cytokine levels in serum and oxidative stress parameters in intestinal tissues, when compared to I/R group of rats. Treatments with GK and KTM, alone and in combination, mitigated the altered mRNA expressions of JNK, ERK, p38 and $N F-k B$ in intestinal tissues of $I / R$-injured rats.

Conclusion: These results reveal that GK potentiates the protective effect of KTM100 on I/R-induced intestinal injury in rats by regulating the NF-kB/ERK/JNK signaling pathway. Therefore, GK and KTM may find use in the management of $I / R$
\end{abstract}

Keywords: Ginkgolide K, Ketamine, Intestinal injury, Ischemia/Reperfusion, Inflammation

\begin{abstract}
This is an Open Access article that uses a fund-ing model which does not charge readers or their institutions for access and distributed under the terms of the Creative Commons Attribution License (http://creativecommons.org/licenses/by/4.0) and the Budapest Open Access Initiative (http://www.budapestopenaccessinitiative.org/read), which permit unrestricted use, distribution, and reproduction in any medium, provided the original work is properly credited.

Tropical Journal of Pharmaceutical Research is indexed by Science Citation Index (SciSearch), Scopus, International Pharmaceutical Abstract, Chemical Abstracts, Embase, Index Copernicus, EBSCO, African Index Medicus, JournalSeek, Journal Citation Reports/Science Edition, Directory of Open Access Journals (DOAJ), African Journal Online, Bioline International, Open-J-Gate and Pharmacy Abstracts
\end{abstract}

\section{INTRODUCTION}

Mesenteric obstruction leads to intestinal ischemia, and it is associated with complications of surgical emergencies such as hypovolemic shock, sepsis and trauma [1]. The mortality of patients suffering from intestinal ischemia has been found to be in the range of 60 to $100 \%$ [2]. The intestine is very sensitive to alterations in blood supply. Intestinal tissue reperfusion enhances the production of cytokines and free radicals which alter gastrointestinal motility and damage the mucosal layer, thereby altering the integrity of 
intestinal tissues [3]. Intestinal I/R also enhances the protein expression levels of adhesion molecules such as ICAM-1 and selectin [4]. Moreover, it has been reported that intestinal contractility is altered by intestinal I/R due to damage to the neurons of myenteric plexus [5]. Intestinal ischemia results in necrosis of intestinal tissues which is managed through surgical excision [6]. However, very few treatment therapies are available for managing intestinal ischemia.

The anesthetic agent ketamine shows promising effect in the treatment of intestinal ischemia [7]. Ketamine, a surface anesthetic agent with antiinflammatory and analgesic properties, pharmacologically antagonizes NMDA receptor [8]. Studies have shown that ketamine exerts dose-dependent protective effect against intestinal I/R, although the molecular mechanisms involved are not yet understood [9]. Ginkgolide $\mathrm{K}$ is a diterpene lactone isolated from Ginkgo biloba [10]. It has been reported that GK mitigates I/R-induced cardiovascular and cerebrovascular disorder [11]. It protects against neuronal injury by reducing oxidative stress and inflammatory markers in the NF-kB pathway [12]. The present study was carried out to determine the synergistic effect of combination of $\mathrm{GK}$ and ketamine on the management of intestinal ischemia/reperfusion injury.

\section{EXPERIMENTAL}

\section{Animals}

Male Sprague-Dawley rats weighing 250-300 g were kept under a 12-h light/12-h dark cycle at $60 \pm 5 \%$ humidity average room temperature of $24 \pm 3{ }^{\circ} \mathrm{C}$. The study was carried out in line with the guidelines of the Association for the Assessment and Accreditation of Laboratory Animal Care International (AAALAC) [13]. The protocols used in the animal study were approved by institutional animal ethical committee of The Second Affiliated Hospital of Xi'an Jiaotong University, China (approval no. IAEC/SAH-XJU/2018/12).

\section{Study design and treatments}

Anesthesia was induced in the rats via i.p. injection of pentobarbital sodium at a dose of 35 $\mathrm{mg} / \mathrm{kg}$. Laparotomy was performed under controlled body temperature. The small intestine was taken out after opening the abdomen. Ischemia was induced through obstruction of the portal vein and superior mesenteric artery for 30 min using microvascular clamps. Then, the clamp was removed to produce reperfusion for $1 \mathrm{~h}$. Ischemia was confirmed by the presence of dark red color and loss of pulse in the intestines. The rats were divided into five different groups: control, I/R and KTM100 groups. The KTM100 group received ketamine at a dose of $100 \mathrm{mg} / \mathrm{kg}$, i.p. $30 \mathrm{~min}$ before the induction of I/R. The GK group received $\mathrm{GK}$ at a dose of $15 \mathrm{mg} / \mathrm{kg}$ i.v. $20 \mathrm{~min}$ before induction I/R. Rats in the KTM100 + GK group received the GK and KTM treatments together $30 \mathrm{~min}$ before the induction of I/R.

Serum was separated by centrifugation of blood withdrawn from each rat at $3000 \mathrm{rpm}$. The serum samples were used to determine biochemical parameters. Moreover, the rats were sacrificed via cervical dislocation, and intestinal tissues were isolated and fixed in 10 $\%$ formaldehyde solution. The intestinal tissues were homogenized in phosphate buffer, $\mathrm{pH} 7.2$, and the homogenate was centrifuged for $30 \mathrm{~min}$ at $3000 \mathrm{rpm}$. The supernatant was removed and stored at $-20^{\circ} \mathrm{C}$.

\section{Determination of cytokines}

The serum levels of the inflammatory mediators i.e. interleukin (IL)-1 $\beta$, IL-6, nuclear factor kappa $\mathrm{B}$ (NF-kB) and tumor necrosis factor (TNF)- $\alpha$ were determined using ELISA commercial kits (R\&D Systems) in accordance with the manufacturer's protocols.

\section{Evaluation of ROS}

MitoSOX red mitochondrial superoxide indicator was used to estimate the intestinal tissue levels of ROS. The tissue homogenates were stained at $37{ }^{\circ} \mathrm{C}$ in the dark for $30 \mathrm{~min}$ with $5 \mu \mathrm{M}$ MitoSOX red. A fluorescent plate reader was used to estimate the intracellular ROS levels at excitation and emission wavelengths of 510 and $580 \mathrm{~nm}$, respectively.

\section{Assessment of oxidative stress}

Malondialdehyde (MDA), nitric oxide (NO), and reduced glutathione (GSH) levels and superoxide dismutase (SOD) activities were estimated in intestinal tissues using ELISA kits according to the manufacturer's instructions.

\section{qRT-PCR}

Trizol Reagent was used to isolate total RNA from intestinal tissues as per the directions given by the manufacturer. Then, reverse transcription kit was used to synthesize cDNA from the RNA as per the instruction given by the 
stress parameters in rats with $\mathrm{I} / \mathrm{R}$-induced intestinal injury.
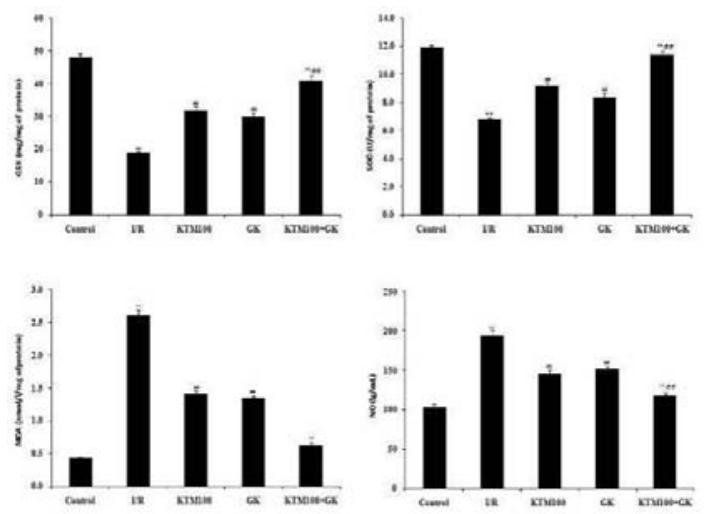

Figure 3: Effect of ginkgolide $\mathrm{K}$ and ketamine treatments on intestinal oxidative stress parameters of rats with I/R- induced intestinal injury: Data are mean \pm SEM ( $\mathrm{n}=10) ; \quad p<0.01$, compared to control group; $\#^{\#} p<0.01$, compared to I/R group; $@^{@} p<0.01$, compared to KTM100 + GK group

Effect of ginkgolide $K$ and ketamine on mRNA expressions of JNK, ERK, p38 and NF-kB

Figure 4 shows the intestinal mRNA expression levels of JNK, ERK, p38 and NF-kB in I/R rats treated with ginkgolide $\mathrm{K}$ and ketamine. There were increases in the mRNA expression levels of JNK, p38 and NF-kB, while the mRNA expression level of ERK was decreased in the intestinal tissue of I/R group, when compared to control group. However, treatments with GK and KTM100, alone and in combination, ameliorated the altered intestinal mRNA expressions of JNK, ERK, p38 and NF-kB. Moreover, GK potentiated the effect of KTM100 on the intestinal expressions of JNK, ERK, p38 and NF-kB in rats with I/R-induced intestinal injury.

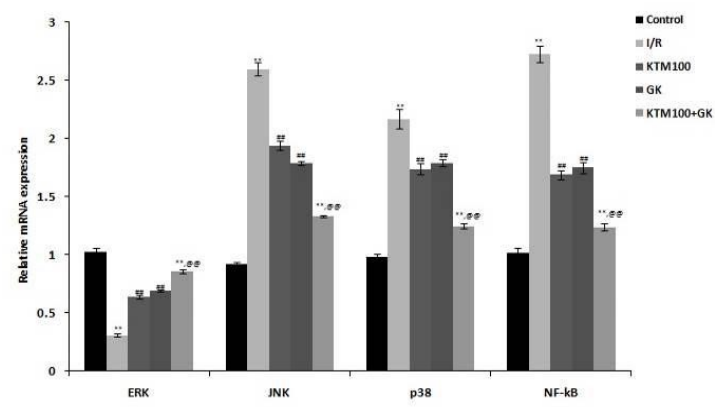

Figure 4: Effect of ginkgolide $K$ and ketamine treatments on the intestinal mRNA expressions of JNK, ERK, p38 and NF-kB in rats with l/R-induced intestinal injury. Data are mean $\pm \operatorname{SEM}(n=10) ;{ }^{* *} p<$ 0.01, compared to control group; ${ }^{\#} p<0.01$, compared to I/R group; ${ }^{@} p<0.01$, compared to KTM100 + GK group

\section{DISCUSSION}

Obstruction of blood supply to the intestinal tissue causes intestinal damage which leads to impairment of the motility of GIT as well as deleterious changes in the mucosal layer [14]. The drugs currently used for the management of obstructed intestinal blood supply have several limitations. Thus, the present study was carried out to determine the effects of ginkgolide $\mathrm{K}$ and ketamine, alone and in combination, on I/Rinduced intestinal injury in rats. The effects of GK and KTM100 were determined by estimating the levels of cytokines in the serum, and parameters of oxidative stress and ROS in the intestinal tissues. Moreover, the intestinal mRNA expressions of JNK, ERK, p38 and NF-kB were determined using qRT-PCR, while histopathological changes were examined using H\&E staining.

Intestinal I/R alters the functions of the intestine as a result of injury due to several factors [15]. For example, I/R induces changes in intestinal motility through some mediators, including $\mathrm{NO}$ [16]. Moreover, parameters of oxidative stress contribute to the pathogenesis of intestinal injury [17]. This is consistent with the results of this study. Treatments with GK and KTM100 (alone and in combination) attenuated the altered parameters of oxidative stress in I/R-induced intestinal injury rats. Ketamine has been reported to protect the intestine against injury [9]. In this study, treatment with GK potentiated the protective effect of ketamine against intestinal injury. It has been reported that the levels of ROS are enhanced in damaged intestinal tissue [18]. In this study, there were reductions in the levels of ROS in rats treated with KTM100 and GK, relative to I/R group of rats.

Cytokines contribute to the development of intestinal injury [19]. Moreover, it has been reported that ketamine reduces the intestinal levels of cytokines, thereby protecting against I/R-induced intestinal injury [9]. The results of the present study suggest that KTM100 and GK treatments (alone and in combination) significantly reduced the levels of cytokines in the intestinal tissues of rats with I/R-induced intestinal injury. Several factors such as p38, ERK and JNK are involved in intestinal injury and cellular apoptosis [20]. The results of this study showed that treatments with KTM100 and GK (alone and in combination) mitigated the changes in mRNA expressions of JNK, ERK, p38 and NF$k B$ in the intestinal tissue of rats with I/R-induced intestinal injury. Moreover, GK potentiated the effect of KTM100 on the expressions of JNK, ERK, p38 and NF-kB in intestinal tissue. 


\section{CONCLUSION}

The results obtained in this study suggest that GK potentiates the protective effect of KTM100 against $\mathrm{I} / \mathrm{R}$-induced intestinal injury in rats by regulating NF-kB/ERK/JNK signaling pathway. Thus, GK could be used clinically for the management of intestinal injury.

\section{DECLARATIONS}

\section{Acknowledgement}

The authors are thankful to the Second Affiliated Hospital of Xi'an Jiaotong University, China for providing the facilities to conduct the presented work.

\section{Conflict of interest}

No conflict of interest is associated with this work.

\section{Contribution of authors}

We declare that this work was done by the authors named in this article and all liabilities pertaining to claims relating to the content of this article will be borne by the authors. Weina Zhu, Zhili Zhao, Xiongtao Liu, performed all the experiments. Xiumei Ni, Xiaoming Lei collected materials and offered help in statistical analysis. Xiaoying Li, Rui Deng gave suggestion in designing this experiments and revision of this manuscript. The whole study was supervised by Liyan Zhao.

\section{Open Access}

This is an Open Access article that uses a funding model which does not charge readers or their institutions for access and distributed under the terms of the Creative Commons Attribution License (http://creativecommons.org/licenses/by/ 4.0) and the Budapest Open Access Initiative (http://www.budapestopenaccessinitiative.org/rea d), which permit unrestricted use, distribution, and reproduction in any medium, provided the original work is properly credited.

\section{REFERENCES}

1. Tilsed JV, Casamassima A, Kurihara $H$, Mariani $D$, Martinez I, Pereira J, Ponchietti L, Shamiyeh A, AlAyoubi F, Barco LA, et al. ESTES guidelines: acute mesenteric ischaemia. Eur J Trauma Emerg Surg 2016; 42(2): 253-270.
2. Aliosmanoglu I, Gul M, Kapan M, Arikanoglu Z, Taskesen $F$, Basol O, Aldemir M. Risk factors effecting mortality in acute mesenteric ischemia and mortality rates: a single center experience. Int Surg 2013; 98(1): 76-81.

3. Bhattacharyya A, Chattopadhyay R, Mitra S, Crowe SE. Oxidative stress: an essential factor in the pathogenesis of gastrointestinal mucosal diseases. Physiol Rev 2014; 94(2): 329-354.

4. Chen JL, Zhou T, Chen WX, Zhu JS, Chen NW, Zhang MJ, Wu YL. Effect of tetramethylpyrazine on P-selectin and hepatic/renal ischemia and reperfusion injury in rats. World J Gastroenterol 2003; 9(7): 1563-1566.

5. Demedts I, Masaoka T, Kindt S, De Hertogh G, Geboes $K$, Farré $R$, Vanden Berghe $P$, Tack J. Gastrointestinal motility changes and myenteric plexus alterations in spontaneously diabetic biobreeding rats. $J$ Neurogastroenterol Motil 2013; 19(2): 161-170.

6. Hasson HM, Galanopoulos C, Langerman A. Ischemic necrosis of small bowel following laparoscopic surgery. JSLS 2004; 8(2): 159-163.

7. Cámara CR, Guzmán FJ, Barrera EA, Cabello AJ, Garcia $A$, Fernández NE, Caballero E, Ancer J. Ketamine anesthesia reduces intestinal ischemia/reperfusion injury in rats. World J Gastroenterol 2008; 14(33): 51925196.

8. Kurdi MS, Theerth KA, Deva RS. Ketamine: Current applications in anesthesia, pain, and critical care. Anesth Essays Res 2014; 8(3): 283-290.

9. Guzmán-De La Garza FJ, Cámara-Lemarroy CR, Ballesteros-Elizondo RG, Alarcón-Galván G, CorderoPérez $P$, Fernández-Garza NE. Ketamine reduces intestinal injury and inflammatory cell infiltration after ischemia/reperfusion in rats. Surg Today 2010; 40(11): 1055-1062.

10. Jaracz S, Malik S, Nakanishi K. Isolation of ginkgolides $A$, $B, C, J$ and bilobalide from $G$. biloba extracts. Phytochemistry 2004; 65(21): 2897-2902.

11. Zhang $R, X u L$, Zhang $D, H u B$, Luo Q, Han D, Li J, Shen C. Cardioprotection of Ginkgolide $B$ on Myocardial Ischemia/Reperfusion-Induced Inflammatory Injury via Regulation of A20-NF-KB Pathway. Front Immunol 2018; 9: 2844.

12. Tang Y, Zhou G, Yao L, Xue P, Yu D, Xu R, Shi W, Yao $X$, Yan Z, Duan JA. Protective effect of Ginkgo biloba leaves extract, EGb761, on myocardium injury in ischemia reperfusion rats via regulation of $T L R-4 / N F-K B$ signaling pathway. Oncotarget 2017; 8(49): 8667186680.

13. Guide for the Care and Use of Laboratory Animals: Eighth Edition Committee for the Update of the Guide for the Care and Use of Laboratory Animals; National Research Council. 2010; ISBN: 0-309-15401-4.

14. Browning $K N$, Travagli RA. Central nervous system control of gastrointestinal motility and secretion and modulation of gastrointestinal functions. Compr Physiol 2014; 4(4): 1339-1368.

Trop J Pharm Res, January 2021; 20(1): 15 
15. Papparella, A., Deluca, F., Oyer, C. Pinar H, Stonestreet $B S$. Ischemia-Reperfusion Injury in the Intestines of Newborn Pigs. Pediatr Res 1997; 42:180-188.

16. Nadatani $Y$, Watanabe $T$, Shimada S, Otani $K$, Tanigawa $T$, Fujiwara $Y$. Microbiome and intestinal ischemia/reperfusion injury. J Clin Biochem Nutr 2018; 63(1): 26-32.

17. Balmus IM, Ciobica A, Trifan A, Stanciu C. The implications of oxidative stress and antioxidant therapies in Inflammatory Bowel Disease: Clinical aspects and animal models. Saudi J Gastroenterol 2016; 22(1): 3-17.
18. Granger $D N$, Kvietys $P R$. Reperfusion injury and reactive oxygen species: The evolution of a concept. Redox Biol 2015; 6: 524-551.

19. MohanKumar K, Namachivayam K, Ho TT, Torres BA, Ohls RK, Maheshwari A. Cytokines and growth factors in the developing intestine and during necrotizing enterocolitis. Semin Perinatol 2017; 41(1): 52-60.

20. Roux PP, Blenis J. ERK and p38 MAPK-activated protein kinases: a family of protein kinases with diverse biological functions. Microbiol Mol Biol Rev 2004; 68(2): 320-344. 